\title{
Resiliência em crianças acolhidas: suas percepções sobre as adversidades
}

Resilience in hosted children: their perceptions of adversities

Resiliencia en niños acogidos: sus percepciones sobre las adversidades

Rosemara Conzatti*

Clarisse Mosmann ${ }^{* *}$

\begin{abstract}
Resumo
Resiliência em Psicologia envolve diferentes aspectos e capacidades das pessoas de superar obstáculos, sendo considerado um fator relevante a ser estudado no contexto do acolhimento institucional. Este estudo de caráter exploratório, descritivo, com delineamento misto, objetivou analisar a relação entre resiliência e fatores de risco e proteção na percepção de crianças em acolhimento institucional. Foi realizado em duas etapas, sendo a primeira por meio de uma escala de resiliência e a segunda, de uma entrevista semiestruturada com dez crianças entre 6 e 12 anos acolhidas na cidade de Porto Alegre. Os resultados apontaram que, apesar de o processo de acolhimento institucional representar risco, foram constatados altos níveis de resiliência. Em seus discursos, eles valorizaram os mecanismos de proteção disponíveis, demonstrando lidar de forma adaptativa com as adversidades. Concluiu-se que os mecanismos de proteção podem ser explorados para promover a resiliência como fator de saúde mental.
\end{abstract}

Palavras-chave: Resiliência psicológica. Criança institucionalizada. Fatores de risco.

\begin{abstract}
Resilience in psychology involves different aspects and abilities of people to overcome obstacles, is considered a relevant factor to be studied in the context of institutional care. This study exploratory, descriptive, with mixed design aimed to analyze the relationship between resilience and risk and protective factors in the perception of children in institutional care. It was conducted in two stages, the first being through a Resilience Scale and the second through a semi-structured interview, with ten children between six and twelve years-old received in the city of Porto Alegre. The results show that although the process of institutional care presents risk for
\end{abstract}

\footnotetext{
Texto recebido em março 2013 e aprovado para publicação em setembro de 2014.

Psicóloga graduada pela Universidade do Vale do Rio dos Sinos (Unisinos). Endereço: Rua Tereza Pezzi, 1011 - Panazzolo, Caxias do Sul-RS, Brasil. CEP: 95098-570.E-mail: roseconzatti@hotmail.com.

* Doutora em Psicologia, professora do Curso e do Programa de Pós-Graduação em Psicologia da Unisinos, psicóloga. Endereço: Avenida Unisinos, 950, São Leopoldo-RS, Brasil. E-mail: clarissepm@unisinos.br.
} 
participants, high levels of resilience were found. In their speeches, they value the protection mechanisms available, demonstrating cope adaptively with adversity. We concluded that the participants cope well with adversity and that the protection mechanisms can be explored to promote resilience as a factor of mental health.

Keywords: Psychological resilience. Child institutionalized. Risk factors.

\section{Resumen}

La resiliencia en psicología corresponde a distintos aspectos y habilidades de las personas para superar obstáculos, siendo considerada un factor importante a ser estudiado en el contexto de acogida institucional. Este estudio exploratorio, descriptivo, con diseño mixto, pretendió analizar la relación entre resiliencia y factores de riesgo y protección en la percepción de los niños en acogida institucional. Se llevó a cabo en dos etapas, la primera a través de una escala de resiliencia y la segunda a través de una entrevista semiestructurada, con diez niños de edades entre seis y doce años, acogidos en la ciudad de Porto Alegre. Los resultados muestran que, aunque el proceso de atención institucional represente riesgo, se constataron altos niveles de resiliencia. En sus discursos ellos valoran los mecanismos de protección disponibles, demostrando hacer frente de forma adaptativa a la adversidad. Se concluyó que los mecanismos de protección pueden ser explotados para la promoción de resiliencia como un factor de salud mental.

Palabras clave: Resiliencia psicológica. Niño institucionalizado. Factores de riesgo.

\section{Introdução}

resiliência é um tema relativamente novo na literatura, intrínseco à relação
humana, e muito importante para a saúde dos indivíduos (Pinheiro, 2004;
Rutter, 1987). Está presente em diversas áreas da saúde, porém é originário da Física e muito usado na Engenharia para designar a capacidade que certos materiais têm de voltar à sua forma original, após sofrer modificaçôes ou impactos do meio externo (Sória et al., 2006).

$\mathrm{Na}$ revisão sistemática de literatura conduzida por Sória et al. (2006), cujo objetivo era mapear os estudos nacionais acerca da resiliência, foi encontrado na base de dados Lilacs um maior número de trabalhos na área das Ciências Sociais, com destaque para pesquisas vinculadas à situação de pobreza, especialmente em moradores de rua, e relacionados à infância e educação. Já nas bases Scielo, tal revisão obteve, como maior número de registros, resiliência e Psicologia, 
seguido de Agronomia e Ciências Sociais. Esses dados indicam a importância desse conceito na Psicologia e a necessidade de entender como a resiliência vem sendo estudada na área.

Já nas décadas de 1980 e 1990, Rutter $(1987,1993)$ conceituou que resiliência é o termo usado para descrever a habilidade que cada pessoa tem de suportar o estresse e as adversidades a ela impostas. Esse autor considera importante salientar que a resiliência não é um conceito estanque, nem mesmo em cada um, mas muda conforme mudam as situações, da mesma forma que, diante de adversidades e situações semelhantes, alguns sucumbem enquanto outros prosperam. Segundo Cyrulnik (2004), a função da resiliência é transformar a dor do momento em uma lembrança gloriosa do passado.

O conceito de resiliência já foi chamado de "invulnerabilidade". Porém o nome foi substituído devido a "invulnerabilidade" dar a impressão de que o indivíduo é insusceptível a riscos ou danos, o que não condiz com a resiliência, em que o sujeito é resistente sim, mas com a noção de que todos têm seus limites (Rutter, 1993). Essas divergências apontam para a falta de consenso na literatura acerca do conceito de resiliência, sendo frequente alvo de discussóes (Pesce et al., 2005; Sória et al., 2006).

A imprecisão conceitual também atinge a inclusão ou não dos fatores de risco e proteção ao conceito de resiliência, já que é inegável o fato de que eles estão interligados. Pinheiro (2004) pontua que a resiliência seria um equilíbrio entre os fatores de risco aos quais o indivíduo foi ou é submetido e os fatores de proteção, tanto sociais (externos) quanto pessoais (internos). Eisenstein e Souza (1993) apontam que os fatores de proteção representam recursos sociais ou pessoais que diminuem os fatores de risco. Os fatores de proteção internos pertencentes aos indivíduos funcionam como habilidades. Esses fatores internos incluem autonomia, motivação, responsabilidade, boas relações interpessoais, bom humor, alta autoestima, entre outros (Garcia, Brino \& Williams, 2009). Os fatores de proteção também podem ser sociais ou externos, como bons níveis de saúde no funcionamento familiar, acesso à educação, disponibilidade de afeto social, bom estado de nutrição, rede de apoio, entre outros (Eisenstein \& Souza, 1993). A supervisão dos pais quanto ao desempenho escolar também foi identificada como um fator de proteção (Garcia et al., 2009). Em crianças resilientes, estudos apontam como fatores de proteção suas características de personalidade, como a autoestima e a flexibilidade. Nesse sentido, também são citadas a coesão familiar e a disponibilidade de suporte externo, como grupos de pares na escola ou na comunidade, que encoraje essa criança e reforce suas estratégias de adaptação (Pesce et al., 2005). 
Por outro lado, Rutter (1993) indica que o conceito "fatores de proteção" não seria o nome correto para o constructo. Melhor seria chamá-los mecanismos de proteção. Isso se deve ao fato de que algumas características podem ser de risco ou de proteção, dependendo do contexto em que atuam. Dessa forma, conceitua-se mecanismo como uma característica atuante em determinada circunstância, que gera determinado resultado. Mecanismos de proteção são aqueles que modificam, melhoram ou alteram a resposta do indivíduo aos riscos e adversidades vividos por esse e traduzem a nocividade de um evento, que previamente seria de risco, porém, se bem conduzido e superado, pode se tornar um impulso para a resiliência (Rutter, 1987). O autor também entende que os conceitos de vulnerabilidade e fatores de proteção são relativos a situações individuais e que são considerados dois polos do mesmo fenômeno. Assim, os fatores de risco incluem os aspectos de vulnerabilidade e proteção. Esta não consiste em evitar o risco, mas em lidar de forma eficaz com este. Mesmo sendo duas faces do mesmo conceito, é importante diferenciá-los, já que cada um tem facetas enriquecedoras à concepção (Rutter, 1987). Portanto os fatores de proteção, a priori, não são fatores de resiliência que convidam a criança ao desenvolvimento (Cyrulnik, 2005).

Quanto aos fatores de risco, apontam-se condutas negativas dos pais como excesso de punição ou falta de dedicação afetiva aos filhos, já que aquelas têm relação com problemas comportamentais e emocionais destes (Garcia et al., 2009). Altos níveis de conflitos familiares também são considerados como fatores de risco, da mesma forma, um relacionamento saudável entre pais e filhos tornase fator de proteção (Mosmann, Zordan \& Wagner, 2011).

Em muitas famílias, a fragilidade das relações, da rede social de apoio e a situação de pobreza podem configurar-se de forma que os pais percam a guarda dos filhos ou ainda que eles mesmos tomem a iniciativa de colocá-los em abrigos. Nesse sentido, a entrada em uma instituição de permanência é uma sobrecarga emocional que não pode ser desprezada em função de situações estressantes como privação da convivência com os pais e adaptação às regras da instituição, que são mais impessoais e, provavelmente, mais rígidas do que as que a criança teria na família (Cavalcante, Magalhães \& Pontes, 2009).

O Estatuto da Criança de do Adolescente (ECA, Lei n. ${ }^{\circ}$ 8.069, 1990) delimita que crianças e adolescentes são prioridades do Estado. Entre os direitos garantidos no estatuto está a proteção contra maus-tratos, a alimentação, o acesso à educação, saúde, políticas sociais, cultura, lazer, cidadania, convivência familiar e comunitária. Em última instância, o Estatuto prevê o acolhimento institucional, por parte do Estado, como medida de proteção. $\mathrm{O}$ relatório do Conselho Nacional do Ministério Público (CNMP, 2013) teve por objetivo 
relatar, conforme previsto na Resolução n. $.^{\circ} 71 / 2011$, a prática de inspeção em serviços de acolhimento brasileiros. Tais serviços são disponibilizados como dever do Estado a crianças e adolescentes que tenham a necessidade de afastarse da família de origem até que esta se restabeleça e possa lhes dar condições mais adequadas de desenvolvimento. Eles podem ser ofertados em diferentes modalidades: abrigos para pequenos grupos, casas-lares, casas de passagem e acolhimento. Focaremos a apresentação de dados sobre abrigos em cujo contexto esta pesquisa foi desenvolvida.

O acolhimento em abrigo deve ocorrer em bairro ou comunidade próxima ao da família de origem ou extensa da criança, em casas com número máximo de 20 de crianças e, ou, adolescentes, para garantir atendimento personalizado. Aos cuidadores é estabelecido que tenham turnos fixos de trabalho para garantir a estabilidade da rotina da casa e dos vínculos, com carga horária mínima de 30 horas semanais e dois cuidadores por turno (Grupo de Trabalho Nacional PróConvivência Familiar e Comunitária [GTNPFC], 2009; Conselho Nacional do Ministério Público [CNMP], 2013).

O relatório do CNMP refere que, em 2013, do universo de 603 instituições de acolhimento da Região Sul inspecionadas pelo órgão, aproximadamente $62 \%$ são abrigos e estes têm capacidade total para 11,1 mil crianças e adolescentes. No Rio Grande do Sul, a capacidade total levantada de atendimentos em abrigo é de cerca de 3.800 atendidos. Desse total, cerca de 2.900 estão preenchidas. Os motivos para o acolhimento em mais de $80 \%$ dos casos são a negligência e, ou, a dependência química dos pais/responsáveis. Outras causas recorrentes são o abandono por parte dos responsáveis, correspondente a $77 \%$ dos casos; a violência, somando cerca de $60 \%$; e o abuso sexual, que fica na faixa de $45 \%$ das ocorrências. Ressalta-se que os motivos podem ser concomitantes, explicando-se assim o total de mais de 100\% (Resolução n. ${ }^{\circ} 71 / 2011,2013$ ).

A Lei n. ${ }^{\circ}$ 12.010/2009, que atualiza o ECA, determina o caráter temporário do acolhimento institucional, que não pode ter duração superior a dois anos, com reintegração familiar progressiva. A situação de acolhimento deve ser revista a cada seis meses, por meio da edição do Plano Individual de Atendimento (PIA), sendo este dever da equipe técnica da entidade responsável pelo programa de acolhimento institucional. No plano, leva-se em consideração a situação familiar atual, iniciativa da família no sentido de retomar a convivência e a opinião da criança ou do adolescente.

Apesar da situação de acolhimento visar à proteção ao desenvolvimento de crianças e adolescentes, abarca uma série de desafios e, na maior parte das muitas vezes, é vivida por elas como algo indesejado e a princípio negativo, 
pois os afasta de suas famílias (Silveira, 2002). Entretanto vivências inerentes aos processos de acolhimento e à distância da família não são, necessariamente, geradores de traumas emocionais, uma vez que cada criança tem sua forma de encarar tais acontecimentos, no processo de adaptação à realidade apresentada (Franco, 2009). Nesse contexto, salienta-se a figura dos cuidadores. Cyrulnik (2005) refere-se aos cuidadores, pais da criança ou cuidadores provisórios, como "tutores de resiliência". Assim, caberia a estes o papel de promover a segurança afetiva e a base de apego necessária ao desenvolvimento saudável das crianças e dos adolescentes. Ou seja, quando o ambiente ao redor da criança se reorganiza, esta pode retomar seu desenvolvimento, como se estima que vinha acontecendo antes do acolhimento.

Em estudo que avaliou o conceito de bem-estar subjetivo como fator de proteção em crianças e adolescentes em vulnerabilidade social, comparando crianças institucionalizadas com outras que vivem com suas famílias, Poletto e Koller (2011) referem que os níveis de satisfação com a vida e afetos positivos não diferem entre os dois contextos. Contudo crianças institucionalizadas indicam maiores níveis de afetos negativos e, com a experiência de ruptura dos laços familiares, a situação de acolhimento pode torná-las ainda mais vulneráveis. Por isso essas crianças necessitam de mais atenção nas intervençôes que promovam bem-estar e qualidade de vida, para que se tornem adultos emocionalmente saudáveis e independentes.

Nesse contexto, é pertinente questionar se seria uma forma de proteção afastar a criança ou o adolescente da família que não apresenta condições de atender a seus cuidados mínimos tanto físicos quanto emocionais. Segundo Becker (1998), o acolhimento institucional só deve ocorrer no caso de essa opção ser a melhor para garantir a integridade física ou psíquica da criança ou do adolescente. Porém o abrigo social aparece sempre em última opção no desejo da criança. Mesmo se comparado a casas familiares em condiçōes extremamente precárias. A "nutrição afetiva” familiar, como cita Silveira (2002), é preferida, apesar da falta de condiçôes físicas e financeiras. Devido aos riscos emocionais aos quais as crianças são submetidas no processo de acolhimento, considera-se a resiliência como um fator de extrema relevância a ser investigado, já que esta demonstra relacionar-se com a forma como os riscos são enfrentados (Garcia et al., 2009; Cyrulnik, 2005).

Yunes (2001), em seu estudo qualitativo com duas famílias de baixa renda e oito profissionais de saúde pública, e que objetivou compreender a resiliência nessas famílias sob uma ótica questionadora da subestimação do fenômeno, conclui que a tal população é atribuída a condição de "não resilientes" pelos trabalhadores sociais de diferentes áreas. Isso pode ocorrer devido à ideologia do 
conceito de resiliência, ao ser aplicado ao contexto de pobreza. O que o estudo demonstra é que tais famílias têm potenciais de resiliência, devido à sua forma de enfrentar os problemas que a pobreza impõe, e um dos fatos que as torna capazes disso é seu jeito de "ser família", que bloqueia as adversidades, tornandoas superáveis. Essa forma de "ser família" também pode ser interpretada como a coesão familiar existente em tais núcleos. Portanto não se pode pressupor que a separação protege a criança, nem que a deixar com a família seria o melhor. Torna-se imprescindível avaliar os diversos aspectos da vida da criança para constatar quais seriam os fatores de resiliência presentes que a auxiliaram no enfrentamento dessa e outras possíveis situações devastadoras (Cyrulnik, 2005).

A complexidade de conceituação da resiliência e a consequente dificuldade em investigá-la se expressa ainda mais na lacuna de estudos sobre resiliência em crianças em situação de acolhimento, escassamente encontrados na literatura nacional e internacional atual, já que a vulnerabilidade em que se encontram é significativa. Por outro lado, Reppold, Mayer, Almeida e Hutz (2012) reforçam, em seu estudo, sobre as formas de mensurar resiliência, a importância de contextualizar os riscos e domínios adaptativos dos sujeitos resilientes, para saber como a resiliência se manifesta diante de determinada situação adversa.

Nesse sentido, em um estudo quantitativo cujo objetivo foi analisar a relação entre resiliência, eventos de vida desfavoráveis e fatores de proteção, feito com 997 adolescentes, entre 12 e 19 anos, da rede pública de ensino da cidade de São Gonçalo, no Rio de Janeiro, Pesce, Assis, Santos e Oliveira (2004) indicam como resultado a não relação entre eventos traumáticos e fatores individuais de resiliência. Isso confirma a hipótese dos autores de que não existe associação direta entre risco e resiliência, já que o mais importante no processo de resiliência é a percepção do indivíduo quanto a tais eventos e a sua capacidade de enfrentálos. Quanto aos fatores de proteção, como esperado pelo estudo, demonstraram associação com os escores de resiliência. Os fatores autoestima, apoio social, sexo e relacionamento interpessoal foram considerados como facilitadores da compreensão e enfrentamento dos fatores de risco susceptíveis aos indivíduos. Os autores trazem a importância da resiliência como um conceito que enfatiza as possibilidades inerentes, não ficando estanque nas desvantagens sociais ou econômicas de uma faixa da população menos favorecida.

Garcia, Brino e Williams (2009) realizaram uma pesquisa com a participação de 107 crianças de baixa renda, entre 10 e 13 anos, com a colaboração das 57 famílias destas. Utilizaram múltiplos instrumentos para medir a resiliência e comparar com estilos parentais, desempenho escolar, entre outros fatores. Como resultados, foram identificados $82 \%$ dos participantes com escores altos de resiliência, sendo que a maior parte destes demonstrou elevada concentração 
e autoestima. Algumas dessas crianças apresentavam vivência de muitos eventos adversos, problemas familiares e financeiros e, mesmo assim, não desenvolveram problemas emocionais e, ou, comportamentais e tinham bom rendimento escolar. Foi observado que duas crianças com os mesmos indicativos de eventos adversos desenvolveram problemas emocionais e, ou, comportamentais segundo as famílias. O estilo parental predominante identificado nas famílias foi classificado como de risco, já que predominavam a punição inconsistente, negligência, disciplina relaxada, monitoria negativa e abuso físico. Entretanto, ainda que esse estilo parental não seja apontado pelas pesquisas como o mais associado ao desenvolvimento saudável dos filhos, as crianças participantes diziam não se sentirem desamparadas por seus cuidadores e tinham altos índices de resiliência.

Esses resultados, aparentemente controversos, indicam a necessidade de mais estudos sobre resiliência, especialmente em situaçôes de vulnerabilidade, uma vez que as pesquisas consideram que as vivências dessas famílias parecem não corresponder ao que é postulado na literatura como fator de risco e seus consequentes reflexos na resiliência das crianças. Além disso, assumindo que a resiliência é um fator que atua na saúde mental, este estudo investigou a presença de indicadores de resiliência e seus possíveis reflexos nos fatores de risco e proteção de crianças acolhidas em abrigos residenciais da cidade de Porto Alegre, por meio de suas percepções e sentimentos sobre condições de vida atual e perspectivas para o próprio futuro.

\section{Método}

\section{Delineamento}

Este estudo teve caráter descritivo exploratório. Foi estruturado e realizado em duas etapas. A primeira teve delineamento quantitativo, com objetivo de mapear os escores de resiliência nas crianças de 6 a 12 anos, acolhidas no NAR Intercap da Fundação de Proteção Especial do Rio Grande do Sul (FPERGS). Esse delineamento permitiu ao estudo um levantamento para conhecer os escores da variável principal, a resiliência (Cozby, 2003). A partir de tal mapeamento, identificaram-se as que tinham escores mais altos de resiliência.

A segunda etapa teve delineamento qualitativo. Essa opção foi em virtude do caráter das variáveis, considerando que tal método possibilitou obter explicações mais amplas sobre variáveis subjetivas (Creswell, 2009). Com os resultados da primeira etapa, buscou-se identificar quais fatores de risco e mecanismos de proteção estiveram presentes na vida das crianças que apresentaram maiores índices de resiliência. Esse delineamento justifica-se pelo intuito de estudar a 
relação entre resiliência, fatores de risco e proteção para as crianças participantes. Concomitante a isso, buscou-se compreender, a partir da visão das crianças, sua percepção dos mecanismos de proteção sociais presentes no meio onde vivem e como elas interagem com esses.

\section{Participantes}

Participaram do estudo, 10 crianças, 5 meninos e 5 meninas, acolhidas em abrigos residenciais da Fundação de Proteção Especial do Rio Grande do Sul (FPERGS). A amostra foi definida por conveniência, por causa do acesso da pesquisadora à instituição. Dentro dos abrigos, os participantes foram selecionados conforme suas idades. O critério de inclusão foi a idade, de 6 a 12 anos, e o de exclusão foi apresentar alguma psicopatologia. A escolha da idade deu-se por causa de a temática do estudo tratar de crianças que, a partir dos 6 anos, já estão inseridas na escola e com condições mínimas de alfabetização, podendo, assim, responder adequadamente aos instrumentos aplicados. Com base na amostra coletada, fez-se a seleção dos participantes que apresentaram maiores escores de resiliência.

\section{Instrumentos}

Na primeira etapa, utilizou-se da escala de resiliência desenvolvida por Wagnild e Young e adaptada ao contexto brasileiro por Pesce et al. (2005), que objetiva medir níveis de adaptação psicossocial positiva perante os acontecimentos importantes na vida por meio de 25 itens descritos de forma positiva, com respostas em escala likert, variando entre 1 (discordo totalmente) e 7 (concordo totalmente). Os escores da escala ocorrem entre 25 a 175 pontos, com valores altos indicando elevada resiliência. Escores de 25 até 75 pontos são considerados baixos. Até 125 pontos, são indicados como índices médios, e os de 126 até os totais 175 pontos, como altos. $\mathrm{O}$ alpha de cronbach obtido pelos autores da escala foi 0,80 .

Como instrumento, na segunda etapa, foi utilizada uma entrevista semiestruturada com as crianças participantes, que teve por objetivo conhecer as percepçôes do participante diante dos fatores de risco sob os quais esse vivia. Da mesma forma, com os mecanismos de proteção sociais ou externos e internos da criança. A entrevista foi baseada em perguntas referentes à moradia anterior ao acolhimento, tanto condiçóes quanto sentimentos e pessoas com quem convivia. Outras quanto aos motivos do acolhimento, se a criança os conhecesse. Também foi questionado sobre as suas percepções, opiniões e sentimentos sobre eventos bons e ruins em suas vidas bem como sobre pessoas que consideram importantes, dentro e fora do abrigo. 


\section{Procedimentos éticos e de coleta de dados}

Para o acesso aos participantes, foi requerida a relação dos acolhidos do NAR Intercap na faixa etária da amostragem de estudo deste projeto (de 6 a 12 anos), e constatou-se a presença, nas casas autorizadas para coleta, de 10 crianças que correspondiam aos critérios de inclusão e exclusão. A pesquisadora fez contato direto com os abrigos residenciais pretendidos, e a coleta dos dados ocorreu nos abrigos onde as crianças viviam, após a assinatura do termo de consentimento livre e esclarecido (TCLE) pela direção da instituição, guardiōes legais das crianças.

$\mathrm{Na}$ primeira visita, foi apresentado o termo de assentimento, a ser assinado pela criança, com a concordância na participação. Nesse encontro, ocorreu a aplicação da escala de resiliência, com cada participante, individualmente. Num segundo momento, foram realizadas as entrevistas com as crianças que participaram da primeira etapa da pesquisa.

Este estudo seguiu as recomendações éticas para a realização de pesquisas com seres humanos, de acordo com as orientaçóes das Resoluçóes n. ${ }^{o}$ 196/1996 do Conselho Nacional de Saúde. Esta prevê que os instrumentos utilizados não representem riscos à saúde física e, ou, psicológica dos participantes. Também foi garantido o sigilo total dos participantes, juntamente com a informação de que a desistência da participação poderia ocorrer a qualquer momento, sem ônus. Esta pesquisa foi submetida ao Comitê de Ética em Pesquisa da Universidade do Vale do Rio dos Sinos (UNISINOS), mediante aprovação e autorização da instituição, local da realização da pesquisa (FPERGS). Outra medida tomada, por considerações éticas, foi a de incluir todas as crianças participantes da primeira etapa também na segunda, mesmo que algumas entrevistas não fossem ser utilizadas nas análises dos dados, por não apresentarem altos escores de resiliência.

\section{Procedimentos de análise de dados}

A escala de resiliência foi corrigida para a verificação dos escores obtidos individualmente pela criança, conforme os procedimentos designados pelos autores da escala (Wagnild e Young, adaptada para o Brasil por Pesce et al., 2005). As dez crianças participantes da pesquisa foram entrevistadas. Entretanto, somente foram analisados os dados das sete entrevistas que obtiveram escores altos de resiliência, assim considerados pelos parâmetros de correção da escala.

Para analisar os resultados da segunda etapa, realizou-se análise de conteúdo segundo Bardin (1979), assumindo categorias definidas a priori a partir de estudos (Eisenstein \& Souza, 1993; Garcia et al., 2009; Pesce et al., 2005; Pinheiro, 2004) que, apesar de terem pequenas divergências na conceituação desses termos, concordam que eles existem e são importantes para o conceito de resiliência. 


\section{Resultados e discussão}

Neste estudo, foram obtidos índices altos de resiliência, entre 134 e 163 pontos (tabela 1) em 7 das 10 crianças que participaram. Os outros 3 participantes, mesmo não tendo atingido índices altos, obtiveram índices considerados médios, entre 100 e 124 pontos, segundo critérios da escala (Pesce et al., 2005). Ou seja, nos participantes deste estudo, nenhum apresentou índice baixo ou médio/ baixo de resiliência. Esse dado condiz com o do estudo de Garcia et al. (2009), feito com crianças de baixa renda, no qual constataram que $82 \%$ da população estudada apresentou altos escores de resiliência.

Tabela 1. Índices de resiliência

\begin{tabular}{lllllll}
\hline Participante & Sexo & Idade & $\begin{array}{l}\text { Tempo de } \\
\text { Ingresso } \\
\text { na data da } \\
\text { entrevista }\end{array}$ & $\begin{array}{l}\text { Pontuação } \\
\text { obtida na } \\
\text { Escala }\end{array}$ & $\begin{array}{l}\text { Escore } \\
\text { obtido } \\
\text { na } \\
\text { Escala }\end{array}$ & $\begin{array}{l}\text { Sabe o motivo } \\
\text { do Ingresso no } \\
\text { Abrigo? }\end{array}$ \\
\hline P1 & Masculino & 9 anos & 9 meses & 163 & Alto & Sim \\
P2 & Masculino & 8 anos & 2 anos & 162 & Alto & Não \\
P3 & Masculino & $\begin{array}{l}11 \\
\text { anos }\end{array}$ & 2 anos & 141 & Alto & Sim \\
P4 & Feminino & $\begin{array}{l}11 \\
\text { anos }\end{array}$ & $\begin{array}{l}\text { Menos de } 1 \\
\text { mês }\end{array}$ & 142 & Alto & Não \\
P5 & Feminino & $\begin{array}{l}6 \text { anos } \\
2 \text { anos }\end{array}$ & 137 & Alto & Não fica claro \\
P6 & Feminino & $\begin{array}{l}12 \\
\text { anos }\end{array}$ & 11 meses & 136 & Alto & Sim \\
P7 & Masculino & $\begin{array}{l}12 \\
\text { anos }\end{array}$ & 7 anos & 134 & Alto & Não \\
P8 & Masculino & 7 anos & 2 anos & 124 & Médio & Não fica claro \\
P9 & Feminino & 9 anos & 1 mês & 114 & Médio & Sim \\
P10 & Feminino & $\begin{array}{l}10 \\
\text { anos }\end{array}$ & 2 anos & 100 & Médio & Sim \\
\hline
\end{tabular}

Fonte: elaborado pelas autoras.

A partir disso, pode-se questionar o conceito usual de que famílias de baixa renda teoricamente não disponibilizariam um ambiente propício para o desenvolvimento saudável das crianças. Ainda que somente com uma medida de resiliência não se possa avaliar todo o processo de desenvolvimento dessas crianças, chamam atenção os altos índices do constructo encontrados. Pode-se pensar, conforme aponta Yunes (2001), que os profissionais sociais e de áreas afins tomam as famílias de baixa renda como "não resilientes", ou seja, sem condiçôes 
de serem provedoras, uma vez que têm uma dinâmica de funcionamento idiossincrática ao seu contexto socioeconômico e cultural a qual não se equivale às famílias de renda média. Entretanto a simples diferença de contexto não pode ser assumida como positiva ou negativa ao desenvolvimento de seus membros.

Os dados da segunda etapa proporcionam um aprofundamento desse mapeamento. Pelas percepçôes das crianças, buscou-se compreender, de forma mais aprofundada, seus processos de resiliência. Com base nas análises de conteúdo das entrevistas, foram assumidas as seguintes categorias:

Tabela 2. Categorias

\begin{tabular}{cc}
\hline Categorias & Subcategorias \\
\hline $\begin{array}{c}\text { 3.1 Categoria I: mecanismos de pro- } \\
\text { teção }\end{array}$ & 3.1 .1 Mecanismos internos \\
3.2 Categoria II: fatores de risco & $\begin{array}{c}3.1 .2 \text { Mecanismos externos ou so- } \\
\text { ciais }\end{array}$ \\
\hline
\end{tabular}

Fonte: elaborado pelas autoras.

\section{Categoria I: mecanismos de proteção}

Essa categoria é definida pelos recursos disponíveis ao indivíduo que tem a possibilidade de diminuir o impacto dos fatores considerados de risco (Eisenstein \& Souza, 1993) bem como episódios e fatos que contribuíram para o desenvolvimento saudável do sujeito. Será chamado "mecanismo" de proteção, em vez de "fator", já que se entende mecanismo como uma característica atuante em determinada circunstância, gerando determinado resultado (Rutter, 1993), ou seja, considera-se o que a criança traz em seu discurso como dado de proteção, causador de bem-estar, seja esse mecanismo interno ou externo.

\section{Mecanismos internos}

Como mecanismos de proteção internos foram consideradas as características de personalidade, como autoestima e flexibilidade (Pesce et al., 2005), além de outras características pessoais disponíveis à criança, que funcionam como habilidades, entre elas autonomia, motivação, responsabilidade e bom humor (Garcia et al., 2009). 
Como mecanismos de proteção internos trazidos pelas crianças, identificamse autoestima e bom humor, demonstrado nos comentários em tom bemhumorado feitos durante a entrevista:

\footnotetext{
"Meus amigos e as tias e os bebês. Acho mais importante... Ah! E a comida... (risos) a comida em último lugar." (P3)

"Entrevistadora (E): Essas pessoas que tu falou, por que tu acha elas mais importantes?

P1: Por que são pessoas legais... Não são egoístas, nem ignorantes.

E: O que é ser ignorante?

P1: Nem eu sei!! (risos) Mas elas não são chatas..."
}

O trecho da entrevista acima demonstra o bom humor do menino (P3) que envolveu risos e assuntos distintos aos questionados, mesmo estando diante de uma entrevista com questóes referentes à temática de sofrimento. O segundo trecho ilustra a autoestima do menino (P1), que, mesmo não sabendo o significado da palavra que havia usado, contornou a situação e deu seu próprio significado a ela, mantendo o bom humor e a capacidade de rir diante de uma possível falha de discurso.

Outra característica aparente nessas crianças é a esperança. Sendo esta demonstrada pelo fato de não salientarem as dificuldades de suas vidas. Quando questionados sobre as dificuldades, apareceram frases como:

"Coisas difíceis? Nem uma coisa quase... Eu acho, não me lembro." (P1)

"Difíceis? Não sei." (P3). 
Da mesma forma, fica evidente que têm esperança quando relatam suas expectativas para o futuro. Por exemplo:

"No meu sonho, foi assim... Andar de bicicleta, fica... Lavando louça... Fica ajudando, fica perto da minha mãe e do meu pai e nunca vir pra cá!" (P5)

"O meu pai agora pegou a minha guarda, e agora ele tem a guarda, e eu vou morar com ele.” (P1)

O sonho aparece como forma de manter as expectativas para o futuro e tornar a realidade, que talvez seja difícil na percepção da menina, temporária. Já a última fala reflete esperança e uma crença de que a situação pode ser diferente. Segundo o relatório do CNMP (2013), o índice de crianças que permanecem nos abrigos por mais de dois anos é de 31\%, nas instituições investigadas. Mesmo com esse dado, considerando que as crianças conhecem as histórias umas das outras, as falas apresentadas anteriormente demonstram que elas mantêm a esperança de um futuro no convívio com suas famílias.

Um dos principais sintomas de bem-estar e bom desenvolvimento observados nas crianças é a preservação da capacidade de brincar e divertir-se com seu mundo de fantasias. Dessa forma, identifica-se essa característica no discurso das crianças:

"Gosto de jogar bola, desenhar, fazer tema, andar de bicicleta, jogar videogame, um monte de coisa... Ir no parque..." (P1)

"E: que tipo de brincadeira tu gosta?

P2: De pega-pega, de esconde-esconde, de todas as brincadeira!" 
As brincadeiras também demonstram flexibilidade. Essa característica foi encontrada, da mesma forma, nas referências às famílias e realidades anteriores, já que, mesmo as considerando, adaptaram-se a sua nova realidade. Isso é demonstrado por um participante (P7) que reforça que "o dia mais legal" foi no abrigo. Essa informação é trazida como fortalecimento pessoal gerado pelos cuidadores institucionais. Outro participante (P3) diz "Aqui é mais legal ainda", sobre o abrigo e as atividades feitas. Com base nessas falas, resgatamos a ideia de Franco (2009) de que o acolhimento institucional não é indicativo direto de sofrimento psíquico, já que cada criança tem sua forma de encarar os acontecimentos e de lidar com a realidade.

Corroborando a ideia de Franco (2009) sobre a relatividade da realidade, dependendo de como o indivíduo a encara, consideramos a fala seguinte como mecanismo de proteção interno:

“[ . . ] meu irmão. Houve um acidente na perna dele. Um ladrão cortou a perna dele. Ficou assim até aqui ó - mostrando o meio da perna. Mas o policial achou o ladrão!” (P2).

Essa fala foi uma das respostas do menino à questão do que ele "considerava legal em sua vida”. O fato poderia ser considerado como difícil para o menino, já que o irmão teria perdido a perna. Entretanto a ressalva de seu discurso foi o fato de tudo ter sido resolvido com o policial, ou seja, ele encontrou uma forma de resolução positiva ao evento, enfatizando em sua fala, que tudo ficou resolvido. Essa resolução representa a relativização do evento pelo participante da pesquisa, o que talvez o auxilie a suportar sua realidade.

Chama atenção, nos dados das entrevistas, o fato de que os afetos negativos aparecem em menor escala do que os positivos e, quando aparecem, não são enfatizados ou, por vezes, poderiam não parecer negativos. Esse fato contradiz o resultado do estudo de Poletto e Koller (2012) o qual aponta que crianças institucionalizadas têm maiores níveis de afetos negativos. Essa contradição aparente pode ser por causa da idade dos participantes. Os participantes do estudo referido tinham entre 7 e 16 anos, enquanto os aqui mencionados tinham entre 6 e 12. Crianças maiores ou adolescentes conseguem expressar-se com mais detalhamento, assim podendo demonstrar, de forma mais elaborada, em seu discurso, os afetos negativos. Essa hipótese foi formulada pela análise do conteúdo das entrevistas, muitas vezes sendo pouco elaboradas, talvez pela idade dos participantes. Por outro lado, considera-se a relativização das crianças quanto aos seus afetos negativos como um fator de proteção. 
Considera-se que os fatores internos são as características que impulsionam a resiliência e estas ajudam o indivíduo a superar as adversidades (Garcia et al., Rutter, 1987). Assim, as expressões encontradas neste estudo corroboram o esperado para crianças resilientes.

\section{Mecanismos externos ou sociais}

Os mecanismos de proteção externos podem funcionar como suportes que encorajem a criança e reforcem suas estratégias (Pesce et al., 2005). Como exemplos, temos o bom funcionamento e a coesão familiar, acesso à educação, disponibilidade de afeto social, bom estado de nutrição, rede de apoio, entre outros (Eisenstein \& Souza, 1993).

Um dos principais mecanismos de proteção externos verbalizados pelas crianças é a família. Nota-se que as crianças continuam a perceber suas famílias como "perfeitas", mantendo as lembranças de afeto, carinho e cuidado muito mais fortes do que qualquer possível situação que as tenha deixado vulnerável. As falas a seguir ilustram o lugar idealizado que a família ocupa no imaginário da criança, o que pode ser uma estratégia que os ajuda a manter as metas e superar as adversidades:

"Eu tenho 28 irmãos! Eu tenho o R., tem o Gu, tenho o Ga, tenho o K., tem o... O M., tem o... O Gu....então é 8! Minha irmã me levava no McDonald's, minha mãe me levava no passeio, no Inter... Era legal!” (P5)

"Eu sentia muitas coisas boas do lado deles, porque eu achava que eles podiam me proteger de algumas coisas que iam acontecer, aí eu gostava muito" (P6)

"Quando tava todos juntos: me sentia bem... Porque eles são mais importantes!" (P4)

Nesse sentido, fica evidente que a falta de condiçōes estruturais e financeiras fica em segundo plano para a criança que prefere a "nutrição afetiva" encontrada na família (Silveira, 2002). A discussão do que seria melhor para as crianças que estão em situação de vulnerabilidade familiar é controversa. É uma forma de proteção afastá-las da família que não está em condições de atender aos cuidados mínimos necessários para a criança? De acordo com Cavalcante, Magalhães e 
Pontes (2009), a instituição é mais impessoal e, provavelmente, apresenta regras mais rígidas do que as que a criança teria com a família. Por outro lado, nesse contexto, elas ficam protegidas da negligência, presente na maior parte dos casos em que as famílias perdem a guarda das crianças, assim como de situações de violência. Ainda assim, para essas crianças, que provavelmente não têm condições de avaliar, em longo prazo, as repercussóes de serem educadas em um contexto de vulnerabilidade, as entrevistas demonstram que as famílias dos participantes continuam sendo vistas de forma idealizada e em um lugar de proteção, carinho e desejo de aproximação, como já apontado no estudo de Yunes (2001). Isso se expressa nas seguintes falas, nas quais as crianças citam as pessoas consideradas mais importantes de sua vida: "Elas são uma família; família é uma coisa legal... A gente fica unido" (P1).

Quanto ao que consideram que foi bom em suas vidas, trazem:

"A escola e os meus amigos, e a minha mãe, e minha família. Que a minha família não é tão pequena, ela era grande, qué dizer, ela é grande." (P2)

"Era bom quando eu ficava com meu pai e minha mãe. Quando minha família tava tudo junto. Era legal. Foi a minha mãe que me carregou na barriga dela, que cuidou de mim, meu pai e minha mãe. Até meus 10 anos.” (P4)

“Me cuidar - pausa - é, me cuidar, me dá carinho." (P4)

Da mesma forma, são nomeadas as pessoas mais importantes da sua vida e a conclusão: "São minha família, em primeiro lugar!” (P3).

Essas falas ilustram a visão que essas crianças têm de suas famílias como rede de apoio e proteção, corroborando o estudo de Garcia et al. (2009), o qual conclui que, apesar do estilo parental dessas famílias não ser o mais adequado de acordo com a literatura, as crianças participantes não se sentiam desamparadas, o que se expressa também em seus altos índices de resiliência. 
Quanto aos grupos de pares ou na comunidade, percebe-se o quanto estes são considerados imprescindíveis em diferentes momentos. Como ilustração, segue a fala de um menino, referindo-se à divisão de lanche e brinquedos que ocorre na escola:

"Eu tenho bastantes amigos! E eu também dô pra eles! Porque eu não posso ficar com uma coisa e não dá uma, tem que dá... Por causa que eles são meus amigos! [...] nós dividimo lanche e brinquedo!" (P2)

A rede de apoio comunitária recebida também aparece:

"Tinha uma vizinha que era muito amiga minha. Daí, a gente sempre brincava lá, às vezes eu ia na casa dela pra comer bolo." (P7)

"Minha madrinha me levou lá... Pra fazer negrinho, bolo... e pra fazer um monte de coisa." (P5)

Sobre os cuidadores institucionais:

"São meus amigos! Me dão bastante coisa, as tias." (P2)

"Elas sabem lidar com a gente. Faz bastante coisa divertida pra gente... Esses dias, ela convidou a gente pra fazer bolo!" (P4)

Da mesma forma, aparecem os amigos do abrigo, muitas vezes considerados “irmãos":

"Eu sei que elas são bem importantes. Tipo assim, uma coisa urgente pra contar pra elas, eu vô lá e conto e elas não contam pra ninguém. Só pras tias, pras tias e pra mais ninguém." (P6) 
Esses conteúdos são compatíveis com o estudo de Pesce et al. (2005), que conclui, entre outros fatores, que as crianças resilientes têm disponibilidade de suporte externo, como grupos de pares na escola ou na comunidade, que as encoraje e reforce suas estratégias de sobrevivência aos desafios impostos. Percebese a importância dada aos cuidadores, tanto família e pais biológicos quanto aos do abrigo, na forma como cada criança fala do carinho e apoio que recebe no abrigo ou que recebeu de sua família enquanto esta esteve mais próxima. Dessa forma, o apoio recebido é mais valorizado do que as possíveis situaçôes difíceis vivenciadas, já que essas ficam subentendidas, não mencionadas. Também podese pensar que as crianças não tenham apontado fatores negativos no abrigo e nos cuidadores por receio quanto a possíveis consequências.

\section{Categoria II: fatores de risco}

A categoria fatores de risco é definida como eventos ou situações potencialmente adversos ocorridos na vida dos indivíduos. Tais situações podem representar sofrimento físico e, ou, psíquico para eles. São apontadas como fatores de risco as condutas negativas dos pais que possam ter relação com problemas emocionais e comportamentais desenvolvidos pelas crianças. Como exemplos dessas condutas, há excesso de punição e falta de dedicação afetiva aos filhos, entre outros (Garcia et al., 2009). Também são considerados fatores de risco os altos níveis de conflito familiares (Mosmann et al., 2011), que, da mesma forma, podem trazer prejuízos para o desenvolvimento dos filhos. A fragilidade no apoio familiar e a pobreza também são entendidas dessa forma na literatura (Rutter, 1987).

Neste estudo, alguns participantes trouxeram, em suas falas, poucos fatores de risco, comparando-se ao esperado devido às suas circunstâncias de vida. Além disso, destacam-se respostas como: "Difícil?... Foi difícil quando eu perdi meu óculos...” (P7).

Esse relato explicita o sofrimento do menino, o que aparentemente não tem nenhuma ligação com o fator de risco. Porém, na continuidade da entrevista, percebe-se que tal fato está relacionado com o medo de punição por parte dos cuidadores, podendo causar sofrimento (Garcia et al., 2009): "Daí a tia disse que eu ia fica umas... Umas duas semanas de castigo... Só ficar no quarto... Sem olhar tevê" (P7). 
Devido à fragilidade no apoio familiar, além das condutas negativas dos cuidadores, somam-se as condutas negativas das próprias crianças:

"Fugia da casa da minha mãe." (P1)

"É que eu não parava em casa, eu saía." (P4)

"Porque eu fugia e fumei uma vez." (P3)

Da mesma forma, aparecem perdas afetivas, como:

"Quando meu pai morreu, eu fiquei chorando! Eu era bebê ainda. Senti uma dor também, no meu peito. Meu vô e minha vó também morreram.” (P2)

"Aí veio a notícia que meu pai tinha tomado um tiro." (P6)

"Meu pai e minha mãe. Só que daí eles se separaram, quando eu era pequeno." (P7)

\section{Violência contra a criança e negligência também são apontadas nas falas:}

"A minha mãe, quando era drogada; eu e minha irmã, a gente tava dentro de casa, e ela não tava em casa, aí a gente ficou um tempo aí esperando, de uma hora pra outra, ela não tava mais em casa." (P6)

"Judiavam de mim - referindo-se a casa da mãe." (P1)

"As outras pessoas sempre me batiam." (P5)

A violência intrafamiliar presenciada pela criança também aparece em algumas falas: "Aí a minha vó veio, 'deu uma tunda nela' (mãe) e botô ela pro hospício" (P6). 
Por outro lado, mesmo em contextos adversos a privação do convívio familiar, também é negativamente marcante:

"Foi difícil, eu não ficá mais perto da minha mãe. Isso é muito ruim, né! A pessoa não ficar do teu lado! A pessoa chora! E um dia eu chorei..." (P5)

“... mas agora 'tá tudo separado', meu irmão tá com meu pai e a namorada, minha irmã tá com o marido dela, meu outro irmão com minha mãe, daí outro em Belo Horizonte e eu... Quando me separei de toda a minha família, me senti um pouco mal.” (P4)

Outra informação obtida neste estudo é o fato de 3 das 10 crianças entrevistadas dizerem claramente não saberem o motivo pelo qual foram retiradas de suas famílias. Apesar de outros participantes não dizerem "não saber", também não souberam esclarecer o motivo:

"Porque eu não gostava do colégio... A professora, ela não deixava a gente ir pro banheiro..." (P9)

"Mais ou menos... A minha mãe queria que eu visse meu pai com ela. Ele tava na cadeia e eu tinha minha carteirinha pra ir visitar ele. Aí eu não quis ir e vim... Eles foram me buscar." (P3)

"Por causa que a minha mãe demorou, demorou pra fazer a casa..." (P8)

"Porque na porta vinha frio, aí minha mãe tava arrumando... Só um dia, porque eu não tinha escola!" (P5)

Alguns participantes disseram saber o porquê do acolhimento e outros não deixaram claro se tinham essa informação ou não. Porém, de forma geral, suas respostas foram vagas, como as citadas acima. Assim, presume-se haver 
outras razões que motivaram tal ação. Esse dado é tomado aqui como fator de risco, já que, sem a informação correta, ou, em alguns casos, sem nenhuma informação sobre o motivo da separação de sua família, a criança fica com poucas possibilidades de entender e elaborar os acontecimentos. No contexto de acolhimento, geralmente isso é feito posteriormente, pela equipe que trabalha diretamente com as crianças, os cuidadores institucionais, porém acredita-se que seria importante dar possibilidades para que a criança pudesse entender o processo desde o início, mesmo havendo grande possibilidade de não o aceitar.

As falas sobre os fatores de risco, ou dificuldades consideradas pelos participantes, foram trazidas com aparente naturalidade, muitas vezes não sendo consideradas exatamente um problema em suas vidas. Essas informações corroboram o estudo de Pesce et al. (2005) de que não existe relação direta entre risco e resiliência, já que o mais importante nesse processo é a percepção do indivíduo quanto a tais eventos e a sua capacidade de enfrentá-los. Portanto, considera-se que a proteção não consiste em evitar possíveis riscos, mas na habilidade de lidar eficazmente com eles (Rutter, 1987).

Uma vez que o objetivo do estudo foi avaliar a percepção das crianças sobre suas vidas, os seus relatos são coerentes com os altos níveis de resiliência que apresentam. $\mathrm{Na}$ percepção dos participantes, os eventos assumidos pela literatura como traumáticos não são avaliados dessa forma, elas não negam a sua existência, mas parecem enfatizar os aspectos positivos de suas vidas, inclusive do acolhimento institucional. Considera-se a hipótese de que, nos discursos, sejam pouco mencionados os eventos traumáticos da vida dos participantes, como mecanismo de proteção para evitar relembrar o sofrimento. Não há como avaliar se tal dinâmica é positiva ou negativa, mas parece ser a maneira que essas crianças encontraram para fazer frente a sua realidade. Neste momento, essa forma de enfrentamento está se refletindo em bons níveis de resiliência, o que, isoladamente, pode ser considerado um bom indicativo.

\section{Considerações finais}

Considerando que a resiliência é um fator que atua na saúde mental, este estudo investigou mecanismos de proteção presentes na vida de crianças com altos níveis de resiliência, acolhidas em abrigos residenciais, bem como os fatores de risco vividos por esses. Os resultados podem ser importantes para a proteção dessa população no momento em que chegarem a seus cuidadores efetivos, que, com essa informação, podem reforçar os mecanismos de proteção externos bem como estimular os mecanismos internos, já existentes em tais crianças. As falas das crianças participantes deste estudo demonstraram que, em muitos momentos, 
embora preferissem estar com a família, o cuidado dos responsáveis do abrigo também era de extrema importância para o seu desenvolvimento.

O discurso mais relevante para este estudo foi o da própria criança, já que, nas entrevistas e outras conversas informais com elas, notou-se como a percepção que elas têm sobre esse fator, a resiliência, é motivador de expectativas para o futuro. Ou seja, acredita-se que a habilidade do indivíduo de se desenvolver perante as adversidades possa motivar mudanças, como estudar, trabalhar, enfim, poder concretizar um futuro que seja desejado por elas.

Não é o objetivo, aqui, criticar o acolhimento institucional dessas crianças, que se sabe ser para sua proteção física e, ou, psíquica. Mesmo porque foi constatado dedicação, cuidado na educação e carinho com os acolhidos. Porém se pode questionar a forma com a qual é feito tal acolhimento, tantas vezes sem nenhuma explicação do que está acontecendo ou do motivo pelo qual essas crianças estão sendo acolhidas. A conversa com as crianças revela essa confusão e ambiguidade, já que carecem de informaçôes sobre o que está acontecendo ou mesmo o porquê de estarem naquele ambiente, sem suas famílias. Com as informações obtidas neste estudo, não é difícil presumir o porquê dos sentimentos ambivalentes quanto a estarem no abrigo, que os acolhe, mas sem um motivo suficientemente esclarecido e que, ao mesmo tempo, retira-os de suas figuras de afeto mais importantes. Salienta-se também que seria muito importante dar à criança um espaço efetivo nas decisões referentes ao seu futuro, como é seu direito, aqui já mencionado.

Com base nos dados obtidos neste estudo, sugere-se o planejamento de intervenções com as famílias dos acolhidos, com o objetivo de que, se estes retornarem ao convívio com elas, possam vivenciar relações mais funcionais do que as que provocaram o acolhimento. A equipe técnica da instituição tem esse trabalho como objetivo, porém, devido à grande demanda e falta de assistência na rede de saúde para as famílias, bem como profissionais que estejam disponíveis para acompanhar efetivamente o andamento destas, tal trabalho fica apenas parcialmente realizado.

Como limitação deste estudo, identifica-se a dificuldade de medir um conceito tão complexo quanto a resiliência. A escala utilizada para medir resiliência tem suas limitações aqui reconhecidas. Sendo originalmente desenvolvida para população adulta, apesar de sua versão brasileira ter sido testada e desenvolvida em população de adolescentes, algumas dimensões ainda parecem inadequados para a população infantil e adolescente. Neste estudo, outra dificuldade foi a de compreensão das perguntas pelas crianças, pela pouca idade e escolaridade, que necessitaram de auxílio para compreender totalmente o que lhes era perguntado 
pela escala. Aponta-se, para futuras pesquisas, a necessidade de utilizar mais de uma medida para avaliar o complexo processo da resiliência (Garcia et al., 2009; Yunes, 2001; Reppold, 2012).

Espera-se que com os resultados apresentados neste estudo, os fatores de risco e proteção possam ser explorados no contexto do acolhimento institucional. Considerando que os cuidadores institucionais e outros profissionais que trabalham diretamente com as crianças acolhidas têm a possibilidade, pelo vínculo afetivo, de promover os mecanismos de proteção, bem como a resiliência, em prol da saúde mental e emocional dos envolvidos.

Conclui-se que a resiliência é um fenômeno importante para o contexto aqui estudado, já que se percebe ser uma característica desenvolvida por esses indivíduos, talvez como forma de enfrentamento adaptativo às adversidades a eles impostas. Nota-se, também, a importância da divulgação de tais resultados visando a promover o desenvolvimento dessa habilidade, que é de extrema relevância para a abertura de futuras possibilidades para essa população, podendo tornar-se mais uma ferramenta de reestruturação social e psicológica para tais indivíduos.

\section{Referências}

Bardin, L. (1979). Análise de conteúdo. L. A. R. \& A. Pinheiro (Trad.). Lisboa: Edições 70.

Becker, M. J. (1998). A ruptura dos vínculos: quando a tragédia acontece. In S. M. Kaloustian (org.). Família brasileira: a base de tudo. (pp. 60-76). Brasília: Cortez, UNICEF.

Cavalcante, L. I. C., Magalhães, C. M. C. \& Pontes, F. A. R. (2009). Processos de saúde e doença entre crianças institucionalizadas: uma visão ecológica. Ciênc. Saúde Coletiva, 14 (2), 615-265. Recuperado a partir de http://www. scielo.br/pdf/csc/v14n2/a30v14n2.pdf.

Cozby, P. C. (2003). Métodos de pesquisa em ciências do comportamento. P. I. C. Gomides \& E. Otta (Trads.). São Paulo: Atlas.

Creswell, J. W. (2009). Research design: qualitative, quantitative and mixed methods approaches. Thousand Oaks, London, New Delhi: Sage. 
Cyrulnik, B. (2004). Os patinhos feios. São Paulo: Martins Fontes.

Cyrulnik, B. (2005). O murmúrio dos fantasmas. São Paulo: Martins Fontes.

Eisenstein, E. \& Souza, R. P. (1993). Situaçôes de risco à saúde de crianças e adolescentes. Petrópolis: Vozes.

Franco, M. E. W. (2009). Possibilidades de viver infâncias: um estudo a partir da ótica de crianças entre 5 e 12 anos. Tese. (Doutorado). Universidade do Vale do Rio dos Sinos, Programa de Pós-Graduação em Educação, Unisinos, São Leopoldo, 2009.

Garcia, S. C., Brino, R. F. \& Williams, L. C. A. (2009). Risco e resiliência em escolares: um estudo comparativo com múltiplos instrumentos. Psicologia da Educação, (28), 23-50. Recuperado a partir de http://pepsic.bvsalud.org/pdf/ psie/n28/v28a03.pdf.

Grupo de Trabalho Nacional Pró-Convivência Familiar e Comunitária. (2009). Orientaçôes técnicas: serviços de acolhimento para crianças e adolescentes. Brasília: Ministério do Desenvolvimento Social e Combate à Fome. Recuperado a partir de: http://www.mds.gov.br/cnas/noticias/orientacoes_ tecnicas_final.pdf

Lei n. ${ }^{\circ}$ 8.069. (1990, 13 de julho). Dispóe sobre o Estatuto da Criança e do Adolescente - ECA, e dá outras providências. Brasília: Presidência da República. Recuperado a partir de http://www.planalto.gov.br/ccivil_03/Leis/ L8069.htm.

Lei n. ${ }^{\circ}$ 12.010. (2009, 3 de agosto). Dispõe sobre adoção, e dá outras providências. Brasília: Presidência da República. Recuperado a partir de http://www.planalto.gov.br/ccivil_03/_ato2007-2010/2009/lei/112010.htm.

Mosmann, C., Zordan, E. P. \& Wagner, A. (2011). A qualidade conjugal como fator de proteção do ambiente familiar. In W. Adriana (Org.). Desafios psicossociais da familia contemporânea. (pp. 58-71, Vol. 1). Porto Alegre: Artmed.

Pesce, R. P., Assis, S. G., Santos, N. \& Oliveira, R. V. C. (2004). Risco e proteção: em busca de um equilíbrio promotor de resiliência. Psicologia: Teoria e Pesquisa, 20 (2), 135-143. Recuperado a partir de: http://www.scielo. $\mathrm{br} / \mathrm{pdf} / \mathrm{ptp} / \mathrm{v} 20 \mathrm{n} 2 / \mathrm{a} 06 \mathrm{v} 20 \mathrm{n} 2 . \mathrm{pdf} /$ 
Pesce, R. P., Assis, S., Avanci, J. Q., Santos, N. C., Malaquias, J. V. \& Carvalhaes, R. (2005). Adaptação transcultural, confiabilidade e validade da escala de resiliência. Cadernos de Saúde pública, 21 (2), 436-448. Recuperado a partir de http://www.scielo.br/pdf/csp/v21n2/10.pdf.

Pinheiro, D. P. N. (2004). A resiliência em discussão. Psicologia em Estudo, 9 (1), 67-75. Recuperado a partir de http://www.scielo.br/pdf/pe/v9n1/ v9n1a09.

Poletto, M. \& Koller, S. H. (2011). Subjective well-being in socially vulnerable children and adolescents. Psicologia: Reflexão e Crítica, 24 (3), 476-484. Recuperado a partir de http://www.scielo.br/pdf/prc/v24n3/a08v24n3.pdf.

Reppold, C. T., Mayer, J. C., Almeida, L. S. \& Hutz, C. S. (2012). Avaliação da resiliência: controvérsia em torno do uso das escalas. Psicologia: Reflexão e Crítica, 25 (2), 248-255. Recuperado a partir de http://www.scielo.br/pdf/ prc/v25n2/a06v25n2.pdf.

Resolução n. ${ }^{\circ}$ 71/2011: um olhar mais atento aos serviços de acolhimento de crianças e adolescentes no país. (2013). Relatório da infância e juventude -Brasília: CNMP. Recuperado a partir de http://www.cnmp.mp.br/portal/ images/stories/Destaques/Publicacoes/Res_71_VOLUME_1_WEB_.PDF.

Rutter, M. (1987). Psychosocial resilience and protective mechanisms. American Journal of Orthopsychiatry, 57 (3), 316-331.

Rutter, M. (1993). Resilience: some conceptual considerations. Journal of Adolescent Health, 14, 626-631.

Silveira, S. C. (2002). Família é para todos? In W. Adriana (Org.). Família em cena: tramas, dramas e transformaçôes. (Cap. 3). Petrópolis: Vozes.

Sória, D. A. C., Santoro, D. C., Souza, I. E., Chagas, M. \& Menezes, M. F. B. (2006). A resiliência como objeto de investigação na enfermagem e em outras áreas: uma revisão. Esc. Anna Nery Rev. Enferm., 10 (3), 547-551. Recuperado a partir de http://www.scielo.br/pdf/ean/v10n3/v10n3a26.pdf.

Yunes, M. A. M. (2001). A questão triplamente controvertida da resiliência em familias de baixa renda. Tese (Doutorado). Pontifícia Universidade Católica de São Paulo, São Paulo. 